\title{
Vida útil de carne bovina moída comercializada no Município de Boa Vista -
}

\section{Roraima}

\author{
Shelf life of ground meat marketed in the Municipality of Boa Vista - Roraima \\ Vida útil de la carne molida vendida en el Municipio de Boa Vista - Roraima
}

\author{
Lévison da Costa Cipriano \\ ORCID: https://orcid.org/0000-0002-2920-7596 \\ Universidade Federal de Roraima, Brasil \\ E-mail: levison_costa@hotmail.com \\ Leiras Benjamin de Sousa \\ ORCID: https://orcid.org/0000-0002-5929-6753 \\ Universidade Federal de Roraima, Brasil \\ E-mail: leirassousa68490@gmail.com \\ Heloisa Pinto de Godoy Siqueira \\ ORCID: https://orcid.org/0000-0001-6585-2325 \\ Universidade Federal de Roraima, Brasil \\ E-mail: heloisa.godoy@ufrr.br \\ Everton Ferreira Lima \\ ORCID: https://orcid.org/0000-0002-5695-8096 \\ Universidade Federal de Roraima, Brasil \\ E-mail: everton.lima@ufrr.br \\ Cassio Toledo Messias \\ ORCID: https://orcid.org/0000-0003-1423-1267 \\ Universidade Federal do Acre, Brasil \\ E-mail: cassio.messias@ufac.br \\ Patrícia Gelli Feres de Marchi \\ ORCID: https://orcid.org/0000-0001-7940-4478 \\ Universidade Federal do Acre, Brasil \\ E-mail: patriciamarchi.ufac@gmail.com \\ Elizabeth Sampaio de Medeiros \\ ORCID: https://orcid.org/0000-0002-1289-2902 \\ Universidade Federal Rural de Pernambuco, Brasil \\ E-mail: elizabeth.medeiros@ufrpe.br \\ Ingrid Bortolin Affonso Lux Hoppe \\ ORCID: https://orcid.org/0000-0002-9946-8820 \\ Universidade Estadual Paulista Júlio de Mesquita Filho, Brasil \\ E-mail: ibaffonso@gmail.com \\ André Buzutti de Siqueira \\ ORCID: https://orcid.org/0000-0002-5880-1578 \\ Universidade Federal de Roraima, Brasil \\ E-mail: andre.siqueira@ufrr.br
}

\begin{abstract}
Resumo
A carne bovina é consumida em todo o mundo, porém de acordo com as características próprias (físicas, química e biológica) podem sofrer processos acentuados de deterioração, assim como serem carreadoras de organismos deterioradores e ou patogênicos. A partir disso, o objetivo deste trabalho foi determinar a vida útil da carne moída comercializada em hipermercados e mercados do município de Boa Vista-RR, por meio de análises sensoriais, $\mathrm{pH}$ e indicadores de contaminação: microrganismos aeróbios mesófilos e aeróbios psicrotróficos. As análises foram realizadas no Laboratório de Produtos de Origem Animal da Universidade Federal de Roraima. Foi realizada a análise sensorial de acordo com características visualizadas no decorrer do armazenamento do produto, o $\mathrm{pH}$ foi determinado por meio do pHmetro e contagem de microrganismos. Dos resultados obtidos, a vida útil da carne moída em relação às análises sensoriais foi em torno de sete dias. O que diz a respeito da qualidade microbiológica da carne moída, segundo a legislação brasileira a carne estava apta para consumo até o décimo dia de armazenamento, com contagens de bactérias mesófilas e psicrotróficas, respectivamente, em torno de 4,3 x $10^{5} \mathrm{UFC} / 25 \mathrm{~g}$ e 4,4 x $10^{5} \mathrm{UFC} / 25 \mathrm{~g}$. Quanto aos valores de $\mathrm{pH}$ da carne apresentavam-se em conformidade com legislação brasileira vigente, apenas no primeiro dia de armazenamento. No entanto, são necessários mais estudos na região a respeito da qualidade da carne moída, que quando comprometida, pode representar perigos à Saúde Pública.
\end{abstract}

Palavras-chave: Contaminação de alimentos; Microrganismos; Qualidade dos alimentos; Saúde pública. 


\begin{abstract}
Beef is consumed all over the world, but according to its own characteristics (physical, chemical and biological) they can undergo marked deterioration processes, as well as being carriers of deteriorating and or pathogenic organisms. From this, the objective of this work was to determine the shelf life of ground meat sold in hypermarkets and markets in the municipality of Boa Vista-RR, through sensory analysis, $\mathrm{pH}$ and contamination indicators: aerobic mesophilic microorganisms and psychrotrophic aerobes. The analyzes were performed at the Animal Products Laboratory at the Federal University of Roraima. Sensory analysis was performed according to characteristics visualized during the product's storage, the $\mathrm{pH}$ was determined by means of a $\mathrm{pH}$ meter and count of microorganisms. From the obtained results, the useful life of the ground meat in relation to the sensorial analyzes was around seven days. What it says about the microbiological quality of ground meat, according to Brazilian legislation, the meat was fit for consumption until the tenth day of storage, with counts of mesophilic and psychrotrophic bacteria, respectively, around $4.3 \times 10^{5}$ $\mathrm{UFC} / 25 \mathrm{~g}$ and $4.4 \times 10^{5} \mathrm{UFC} / 25 \mathrm{~g}$. As for the $\mathrm{pH}$ values of the meat, they were in compliance with current Brazilian legislation, only on the first day of storage. However, further studies are needed in the region regarding the quality of ground beef, which when compromised, can pose dangers to Public Health.
\end{abstract}

Keywords: Food contamination; Food quality; Microorganisms; Public health.

\title{
Resumen
}

La carne de vacuno se consume en todo el mundo, pero según sus propias características (físicas, químicas y biológicas) pueden sufrir marcados procesos de deterioro, además de ser portadoras de organismos deteriorantes yo patógenos. A partir de ello, el objetivo de este trabajo fue determinar la vida útil de la carne picada comercializada en los hipermercados y mercados del municipio de Boa Vista-RR, mediante análisis sensorial, indicadores de $\mathrm{pH}$ y contaminación: microorganismos mesófilos aeróbicos y aerobios psicrotróficos. Los análisis se realizaron en el Laboratorio de Productos Animales de la Universidad Federal de Roraima. El análisis sensorial se realizó de acuerdo a las características visualizadas durante el almacenamiento del producto, el pH se determinó mediante el medidor de pH y el recuento de microorganismos. De los resultados obtenidos, la vida útil de la carne picada en relación a los análisis sensoriales fue de alrededor de siete días. Lo que dice sobre la calidad microbiológica de la carne picada, según la según la ley brasileña, la carne estaba apta para el consumo hasta el décimo día de almacenamiento, con recuentos de bacterias mesófilas y psicrotróficas, respectivamente, alrededor de 4,3 x $10^{5} \mathrm{UFC} / 25 \mathrm{~g}$ y 4,4 x $10^{5}$ UFC/25g. En cuanto a los valores de pH de la carne, cumplieron con la legislación brasileña vigente, solo el primer día de almacenamiento. Sin embargo, se necesitan más estudios en la región con respecto a la calidad de la carne molida de res, que, cuando se ve comprometida, puede representar un peligro para la salud pública.

Palabras clave: Calidad de los alimentos; Contaminación de alimentos; Microorganismos; Salud pública.

\section{Introdução}

Segundo Ornellas (2001), carne é todo músculo que reveste o esqueleto dos seres vivos. Sendo a carne moída, uma das formas de cortes bovino bastante popular no Brasil, por apresentar alta praticidade na hora do preparo e baixo custo (Ferreira \& Simm, 2012).

De acordo com a Instrução Normativa nº 83 (Brasil, 2003), por definição, a carne moída é o produto cárneo cru resultante da moagem de músculos provenientes de carcaças de bovinos, submetidas posteriormente ao processo de resfriamento ou congelamento.

Apesar dos seus benefícios, a carne moída propicia o desenvolvimento de microrganismos, incluindo os patogênicos, isso devido as suas características intrínsecas e a sua má conservação (Brasil, 1997). No intuito de minimizar as perdas do produto, adota-se a refrigeração da carne fresca logo após o abate, permanecendo a mesma sob as mesmas condições durante o transporte, manipulação, até ser armazenada na geladeira do consumidor (Roça, 2008).

Dentre os principais microrganismos que indicam a qualidade sanitária dos alimentos destacam-se os psicrotróficos, mesófilos, termófilos, coliformes totais e termo tolerantes, Escherichia coli, Staphylococcus aureus, Enterococos spp. (Silva, 2002).

Os microrganismos aeróbios mesófilos é um grupo de bactérias que se multiplicam entre $10^{\circ} \mathrm{C}$ e $45^{\circ} \mathrm{C}$, tendo preferência por temperaturas em torno de $30^{\circ} \mathrm{C}$. Possuem grande relevância no cenário alimentício, pois estão presentes na maioria dos contaminantes de produtos de origem animal, atingindo contagens altíssimas quando o alimento permanece sob temperatura ambiente. São muito utilizados para detectar falhas de sanitização, mudanças bruscas na temperatura de 
refrigeração, falta de controle no descongelamento dos alimentos e na determinação do tempo de vida útil do produto (Cunha, 2018; Barbosa, 2020).

Já os microrganismos aeróbios psicrotróficos, são bactérias que se multiplicam abaixo dos $7^{\circ} \mathrm{C}$, ou seja, em temperaturas baixas, tendo como preferência temperaturas entre 20 e $30^{\circ} \mathrm{C}$, assumindo um papel importante em alimentos armazenados sob refrigeração. Causam grandes prejuízos na indústria de leite e derivados, pois podem atuar no leite pasteurizado e cru, multiplicando-se e alterando características como cor, odor e sabor. E são comumente encontradas na água e em vasilhas que não foram higienizadas corretamente (Oliveira et al., 2012).

As toxinfecções alimentares são o reflexo direto das condições higiênico-sanitárias dos alimentos. A contaminação dos alimentos pode ocorrer durante a fase de manipulação, equipamentos ou no ambiente utilizado na preparação do alimento (Souza \& Silva, 2004). A partir disso, o objetivo deste trabalho foi avaliar a vida útil da carne moída provenientes de hipermercados e mercados de bairros no município de Boa Vista-RR, mantidas sob refrigeração, bem como a qualidade microbiológica dessas carnes.

\section{Metodologia}

Esta pesquisa foi desenvolvida no ano de 2018. Foram escolhidos quatro hipermercados $(1,2,3,4)$ originando a amostra A, e quatro mercados de bairros $(5,6,7,8)$, resultando na amostra B, todos situados no município de Boa Vista - RR. Em cada estabelecimento foram adquiridos 500 gramas de carne moída em embalagens próprias dos estabelecimentos, simulando o cotidiano.

Em seguida foram identificadas, acondicionadas em caixa isotérmica contendo gelo e encaminhadas ao Laboratório de Produtos de Origem Animal da Universidade Federal de Roraima.

No laboratório, foi realizado um pool das amostras, distinguindo entre hipermercados e mercados de bairro. Para isso, as amostras oriundas dos hipermercados foram colocadas em um saco plástico esterilizado em micro-ondas, totalizando 2 $\mathrm{kg}$ de carne, e massageadas por 2 minutos, a fim de homogeneizar os produtos de estabelecimentos distintos, resultando na amostra A. Então foram acondicionadas em vasilha de plástico com tampa, armazenadas sob refrigeração $\left( \pm 4^{\circ} \mathrm{C}\right)$. Os mesmos processos foram realizados com as carnes provenientes dos mercados de bairros, originando a amostra B.

$\mathrm{O}$ dia da coleta foi denominado dia 0 e a cada 72 horas (Tabela 1) foram realizadas a análises sensoriais, $\mathrm{pH} \mathrm{e}$ microbiológicas (microrganismos aeróbios mesófilos e microrganismos aeróbios psicrotróficos). Para tanto foram realizadas em intervalos de tempo (D0, D1, D2, D3, D4, D5, D6 e D7), totalizando oito amostras de hipermercados e oito amostras de mercados de bairros, totalizando 16 amostras em 19 dias de armazenamento. 
Tabela 1. Representação dos dias de armazenamento da carne moída de hipermercados e mercados de bairros em relação aos intervalos de tempo (D0, D1, D2, D3, D4, D5, D6, D7), no Município de Boa Vista/RR.

\begin{tabular}{|c|c|}
\hline Armazenamento (dias) & Tempo das análises \\
\hline 1 & \\
\hline 2 & D0 \\
\hline 3 & \\
\hline 4 & \\
\hline 5 & D1 \\
\hline 6 & \\
\hline 7 & \\
\hline 8 & D2 \\
\hline 9 & \\
\hline 10 & \\
\hline 11 & D3 \\
\hline 12 & \\
\hline 13 & \\
\hline 14 & D4 \\
\hline 15 & \\
\hline 16 & \\
\hline 17 & D5 \\
\hline 18 & \\
\hline 19 & D \\
\hline 20 & D6 \\
\hline 21 & \\
\hline 22 & D7 \\
\hline
\end{tabular}

Fonte: Autores.

Para a análise sensorial, as características da carne moída de hipermercados e mercados de bairros, como: cor, odor, aparência, textura, presença de muco foram avaliadas no presente estudo. Utilizando-se como critério de avaliação, através de pontuações: $0,1,2$ e 3 , conforme Tabela 2 .

Tabela 2. Representação do critério de avaliação sensorial das carnes moídas de hipermercados e mercados de bairros, segundo sistema de pontuações $(0,1,2,3)$.

\begin{tabular}{|c|c|c|c|c|}
\hline Característica & $\mathbf{0}$ & 1 & 2 & 3 \\
\hline Odor & Bom & Regular & Ruim & Péssimo \\
\hline Aparência & $\begin{array}{l}\text { Muito } \\
\text { Brilhante }\end{array}$ & Brilhante & Pouco Brilhante & Opaca \\
\hline Textura & $\begin{array}{c}\text { Muito } \\
\text { Consistente }\end{array}$ & Consistente & Pouco consistente & Amolecida \\
\hline Coloração & $\begin{array}{l}\text { Vermelho } \\
\text { vivo }\end{array}$ & $\begin{array}{c}\text { Vermelho vivo com poucas áreas } \\
\text { marrons }\end{array}$ & $\begin{array}{l}\text { Levemente } \\
\text { marrom }\end{array}$ & Marrom \\
\hline Muco & Ausente & Presença discreta & $\begin{array}{c}\text { Presença } \\
\text { acentuada }\end{array}$ & $\begin{array}{l}\text { Presença } \\
\text { exagerada }\end{array}$ \\
\hline
\end{tabular}

As pontuações mais altas indicam que a carne estava em avançado estado de deterioração, enquanto que pontuações baixas, a carne encontra-se em condições apropriadas para o consumo.

Amostras que receberam a pontuação zero na maioria das suas características indicam que naquele momento, o produto está apto para consumo. As amostras que receberam a pontuação um, suas características estão entre o limiar de bom a ruim. Já as amostras que receberam pontuação dois, indicam características não desejáveis na carne moída. Enquanto as amostras que receberam a pontuação três estão em avançado estado de deterioração. 
O pH das amostras foi determinado através do pHmetro Lucadema, modelo MPA210. As análises microbiológicas foram realizadas a partir da quantificação de microrganismos mesófilos e psicrotróficos em duplicata, seguindo a metodologia proposta por Downes e Ito (2001).

Foi utilizado um Delineamento Inteiramente Casualizado (DIC) com duas parcelas de amostras independentes. Para os comparativos entre hipermercados e mercados de bairros foi utilizado o teste $\mathrm{T}$.

\section{Resultados e Discussão}

\section{Análise sensorial da carne moída}

$\mathrm{Na}$ Tabela 3, dispõem-se os resultados das características sensoriais avaliadas nas amostras de hipermercados do início ao final do estudo.

Tabela 3. Avaliação sensorial da carne moída de hipermercados ao longo do tempo de armazenamento, no município de Boa Vista-RR.

\begin{tabular}{c|cccccccc}
\hline \multicolumn{7}{c}{ Hipermercado (Dia) } \\
\hline Avaliação & D0 & D1 & D2 & D3 & D4 & D5 & D6 & D7 \\
\hline Odor & Bom & Bom & Bom & Regular & Ruim & Péssimo & Péssimo & Péssimo \\
Aparência & $\begin{array}{c}\text { Muito } \\
\text { Trilhante }\end{array}$ & Brilhante & Brilhante & $\begin{array}{c}\text { Pouco } \\
\text { Brilhante }\end{array}$ & $\begin{array}{c}\text { Pouco } \\
\text { Brilhante }\end{array}$ & $\begin{array}{c}\text { Pouco } \\
\text { Brilhante }\end{array}$ & Opaca & Opaca \\
Cuito & $\begin{array}{c}\text { Muito } \\
\text { Consistente } \\
\text { Consistente }\end{array}$ & Consistente & $\begin{array}{c}\text { Pouco } \\
\text { consistente }\end{array}$ & Friável & Friável & Friável & Friável \\
Mução & $\begin{array}{c}\text { Vermelho } \\
\text { vivo }\end{array}$ & $\begin{array}{c}\text { vivo com } \\
\text { poucas áreas } \\
\text { marrons }\end{array}$ & $\begin{array}{c}\text { Levemente } \\
\text { marrom }\end{array}$ & $\begin{array}{c}\text { Levemente } \\
\text { marrom }\end{array}$ & $\begin{array}{c}\text { Levemente } \\
\text { marrom }\end{array}$ & Marrom & Marrom & Marrom \\
Ausente & Ausente & Ausente & $\begin{array}{c}\text { Presença } \\
\text { discreta }\end{array}$ & $\begin{array}{c}\text { Presença } \\
\text { acentuada }\end{array}$ & $\begin{array}{c}\text { Presença } \\
\text { acentuada }\end{array}$ & $\begin{array}{c}\text { Presença } \\
\text { exagerada }\end{array}$ & $\begin{array}{c}\text { Presença } \\
\text { exagerada }\end{array}$ \\
\hline
\end{tabular}

Fonte: Autores.

Observamos que as amostras até o D2 (sete dias de armazenamento) a carne ainda estava em boas condições para consumo, independente do local de compra. Apresentando características como: odor (bom) característico de carne moída; aparência brilhante; textura consistente; coloração levemente marrom e ausência de muco. Mudanças visíveis e acentuadas foram visualizadas no D3 (décimo dia de armazenamento), apresentando características como: odor regular; aparência pouco brilhante; textura pouco consistente; coloração marrom e muco discreto. Enquanto no vigésimo segundo dia da avaliação (D7), a carne estava totalmente deteriorada, apresentando: péssimo odor; aparência opaca; textura friável; coloração marrom e muco intenso.

$\mathrm{Na}$ Tabela 4, encontram-se os resultados das análises sensorias das amostras de carne moída de mercados de bairros do início ao final do estudo.

Tabela 4. Avaliação sensorial da carne moída de mercados de bairros ao longo do tempo de armazenamento, no município de Boa Vista/RR. 
Fonte: Autores.

\begin{tabular}{|c|c|c|c|c|c|c|c|c|}
\hline \multicolumn{9}{|c|}{ Mercado de bairro (Dia) } \\
\hline Avaliação & D0 & D1 & D2 & D3 & D4 & D5 & D6 & D7 \\
\hline Odor & Bom & Bom & Bom & Regular & Péssimo & Péssimo & Péssimo & Péssimo \\
\hline Aparência & Muito Brilhante & Brilhante & Brilhante & $\begin{array}{l}\text { Pouco } \\
\text { Brilhante }\end{array}$ & $\begin{array}{c}\text { Pouco } \\
\text { Brilhante }\end{array}$ & Opaca & Opaca & Opaca \\
\hline Textura & Muito Consistente & $\begin{array}{c}\text { Muito } \\
\text { Consistente }\end{array}$ & Consistente & Friável & Friável & Friável & Friável & Friável \\
\hline Coloração & Vermelho vivo & $\begin{array}{l}\text { vermelho } \\
\text { vivo com } \\
\text { poucas } \\
\text { áreas } \\
\text { marrons }\end{array}$ & $\begin{array}{l}\text { Levemente } \\
\text { marrom }\end{array}$ & $\begin{array}{l}\text { Levemente } \\
\text { marrom }\end{array}$ & Marrom & Marrom & Marrom & Marrom \\
\hline Muco & Ausente & Ausente & Ausente & $\begin{array}{c}\text { Presença } \\
\text { discreta }\end{array}$ & $\begin{array}{l}\text { Presença } \\
\text { acentuada }\end{array}$ & $\begin{array}{l}\text { Presença } \\
\text { acentuada }\end{array}$ & $\begin{array}{c}\text { Presença } \\
\text { exagerada }\end{array}$ & $\begin{array}{r}\text { Presença } \\
\text { exagerada }\end{array}$ \\
\hline
\end{tabular}

Levando em consideração, a vida útil da carne moída proveniente de hipermercados e mercados de bairro, mantida sob refrigeração, de acordo com as análises sensoriais é próxima de sete dias.

O odor desagradável (regular, ruim e péssimo), é devido ao acúmulo de ácido láctico e a decomposição de proteínas constituintes da carne, decorrente da multiplicação microbiana. De acordo com Bandeira (2004) conforme ocorre a proteólise, substâncias fétidas são produzidas, como por exemplo, amônia, H2S, amina e outros compostos.

A aparência brilhante na carne está diretamente relacionada com incidência de luz na carne. Nos primeiros dias de armazenamento as miofibrilas ainda estão íntegras, fazendo com que a luz seja espalhada na superfície da carne, resultando em uma carne mais brilhante. Quando ocorre a deterioração da carne, sabe-se que as miofibrilas não estão mais íntegras devido a proteólise, o que faz com que a luz penetre profundamente na carne, sem haver o espalhamento dessa luz, que a olho nu é perceptível uma carne escura e opaca.

A textura da carne consiste e estar relacionada com o tamanho dos feixes das fibras musculares, a gordura e a capacidade de retenção de água. A capacidade de retenção de água (CRA) é a capacidade da carne em reter sua própria água durante a aplicação de forças externas, como cortes, aquecimento, trituração e prensagem (Aberle et al., 2001).

A coloração vermelha da carne é devido à presença de pigmentos, como a hemoglobina e a mioglobina. Quando a cor da carne torna-se marrom, significa que ocorreu a multiplicação de microrganismos que utilizam como substrato a mioglobina. Então a ligação do grupo heme (responsável pela cor da carne) com a globina é desfeita, tornando a carne marrom.

Segundo Mancini e Hunt (2005) a carne in natura em condições de baixas concentrações de oxigênio, favorece o processo de oxidação no átomo de ferro (íon ferroso) presente no grupo heme, em íon férrico. Resultando assim, na formação de metamioglobina que por sua vez, não se liga ao oxigênio, tornando a carne marrom.

O aparecimento de muco na superfície da carne está relacionado com as variações de temperatura no ambiente refrigerado e a quantidade de água livre disponível na carne. Certos tipos de microrganismos, como por exemplo, a bactéria Pseudomonas spp. multiplicam-se nos alimentos com alta atividade de água, produzindo como consequência da multiplicação, o muco (Bandeira, 2004).

\section{Avaliação do pH da carne moída ao longo do armazenamento}

$\mathrm{O}$ pH da carne colhida nos hipermercados apresentou o valor mínimo de 6,1 e o valor máximo de 6,9 (Tabela 5). Enquanto o pH das amostras de carne recolhidas em mercados de bairros apresentou valor mínimo de 5,9 e o valor máximo de 
7,5. Os valores iniciais do pH no D0 (primeiro dia de armazenamento), para hipermercados e mercados estão em conformidade com a legislação brasileira, que varia de 5,8 a 6,2, estando aptas ao consumo humano (Brasil, 1981).

Tabela 5. Distribuição das amostras de carne moída de hipermercados (A) e mercados de bairros (B) no município de Boa Vista/RR, segundo valores de $\mathrm{pH}$ ao longo do tempo de armazenamento.

\begin{tabular}{ccc}
\hline & & pH \\
\hline Tempo & A & B \\
\hline D0 & 6,1 & 5,9 \\
D1 & 5,5 & 5,5 \\
D2 & 5,4 & 5,5 \\
D3 & 6,4 & 6,6 \\
D4 & 6,9 & 7,2 \\
D5 & 6,9 & 7,5 \\
\hline
\end{tabular}

Fonte: Autores.

Após o D0, a carne moída não atendeu os limites estabelecidos pela legislação brasileira quanto ao valor de $\mathrm{pH}$, estando inapta para consumo. Resultados semelhantes foram encontrados por Mach et al. (2008) apresentando valores entre 5,4 a 5,8. Já Conceição \& Gonçalves (2009) encontraram valores de pH na faixa de 6,5 e 7. Souza et al. (2020) realizou a análise físico-química e microbiológica da carne moída comercializada em açougues de três bairros do Macapá- Amapá e verificou que dos seis estabelecimentos, pelo menos quatro deles possuíam carne com $\mathrm{pH}$ fora do limite estabelecido pela a legislação brasileira.

A carne com o pH entre 5,8 e 6,2 mantém todas as características de um produto apto para consumo, como: odor agradável, textura consistente, coloração vermelho vivo, além de estabilidade microbiológica (Brasil, 1981). No entanto, este parâmetro analisado individualmente, sem outros parâmetros envolvidos, não indica exatamente o grau de deterioração das carnes. Essa afirmação é justificada no estudo realizado por Skrökki (1997) que encontrou valores de pH 5,5 e 6,2 que não correspondiam com a alta carga de bactérias aeróbias de $10^{7}$ e $10^{8} \mathrm{UFC} / \mathrm{g}$.

$\mathrm{O}$ pH abaixo de 5,8 encontrado no presente estudo é devido a multiplicação de bactérias ácido láticas psicrotróficas, que resulta no acúmulo de ácido lático na carne. Isso ocorre porque essas bactérias por estarem em um ambiente refrigerado possuem uma taxa de multiplicação maior se comparada a outros microrganismos. Já o pH acima de 6,2 encontrado no presente estudo é indicativo de que as bactérias aeróbias mesofílicas estão atuando na deterioração do alimento.

Na Figura 1, estão dispostos os resultados obtidos pelo teste $T$, comparando amostras de carne moída de hipermercados e mercados de bairros em relação ao $\mathrm{pH}$. 
Figura 1. Representação esquemática das amostras de carne moída de hipermercados e mercados de bairros no município de Boa Vista/RR, segundo valores de $\mathrm{pH}$ ao longo do tempo de armazenamento.

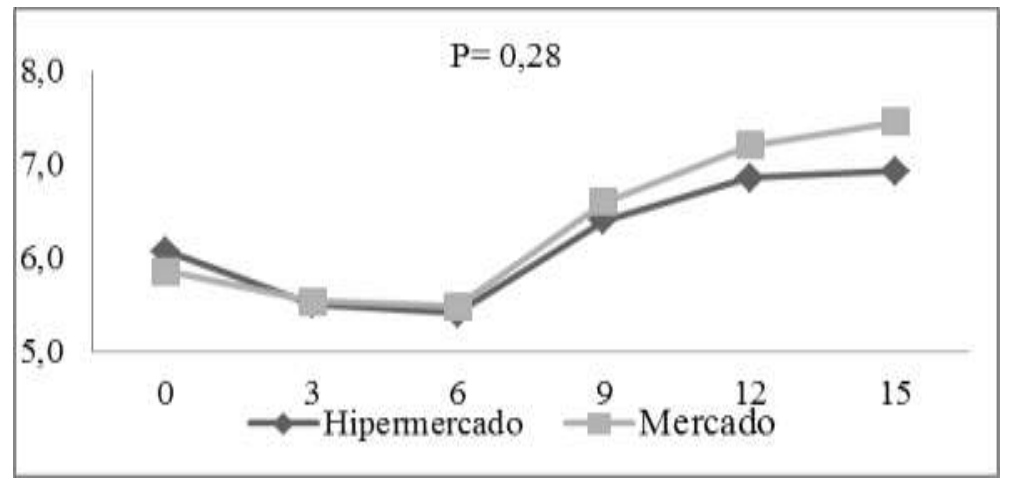

*efeito não significativo (teste T amostras pareadas independentes, $\alpha=0,05$ ). Fonte: Autores.

O resultado fornecido pelo teste $\mathrm{T}$ para amostras independentes, o comparativo entre amostras de carne moída de hipermercados e mercados de bairros em relação ao $\mathrm{pH}$, não apresentou diferenças significativas estatisticamente $(\mathrm{p}<0,05)$.

\section{Microbiologia da carne moída ao longo do armazenamento}

Na Tabela 6, a contagem de microrganismos aeróbios mesófilos para hipermercados o valor mínimo foi 2,9 x $10^{5}$ UFC/25g e o máximo $1,3 \times 10^{7} \mathrm{UFC} / 25 \mathrm{~g}$. Enquanto a contagem de microrganismos aeróbios mesófilos para mercados de bairros o valor mínimo foi $2,8 \times 10^{5} \mathrm{UFC} / 25 \mathrm{~g}$ e o máximo $4,4 \times 10^{7} \mathrm{UFC} / 25 \mathrm{~g}$.

Os resultados para microrganismos aeróbios psicrotróficos para hipermercados o valor mínimo foi 3,7 x $10^{5} \mathrm{UFC} / 25 \mathrm{~g}$ e o máximo 1,4 x $10^{7} \mathrm{UFC} / 25 \mathrm{~g}$ (Tabela 6). Enquanto os microrganismos aeróbios psicrotróficos para mercados de bairros o valor mínimo 4,4 x $10^{5} \mathrm{UFC} / 25 \mathrm{~g}$ e o máximo $1,6 \times 10^{7} \mathrm{UFC} / 25 \mathrm{~g}$.

Tabela 6. Distribuição das amostras de carne moída de hipermercados (A) e mercados de bairros (B) no município de Boa Vista/RR, segundo valores de contagem padrão em placas de microrganismos aeróbios mesófilos e psicrotróficos ao longo do tempo de armazenamento.

\begin{tabular}{|c|c|c|c|c|}
\hline \multirow[b]{2}{*}{ Tempo } & \multicolumn{2}{|c|}{$\begin{array}{l}\text { Microrganismo Aeróbios } \\
\text { Mesófilos (UFC/g) }\end{array}$} & \multicolumn{2}{|c|}{$\begin{array}{l}\text { Microrganismo Aeróbios } \\
\text { Psicrotróficos (UFC/g) }\end{array}$} \\
\hline & A & B & $\mathbf{A}$ & B \\
\hline D0 & $2,9 \times 10^{5}$ & $2,8 \times 10^{5}$ & $3,7 \times 10^{5}$ & $4,4 \times 10^{5}$ \\
\hline D1 & $2,2 \times 10^{5}$ & $2,5 \times 10^{5}$ & $3,7 \times 10^{5}$ & $4,1 \times 10^{5}$ \\
\hline D2 & $3,5 \times 10^{5}$ & $2,2 \times 10^{5}$ & $4,3 \times 10^{5}$ & $4,7 \times 10^{5}$ \\
\hline D3 & $4,5 \times 10^{5}$ & $4,6 \times 10^{5}$ & $4,3 \times 10^{5}$ & $4,4 \times 10^{5}$ \\
\hline D4 & $2,8 \times 10^{6}$ & $3,9 \times 10^{6}$ & $3,2 \times 10^{6}$ & $2,9 \times 10^{6}$ \\
\hline D5 & $6,0 \times 10^{6}$ & $5,7 \times 10^{6}$ & $1,6 \times 10^{7}$ & $1,7 \times 10^{7}$ \\
\hline D6 & $6,3 \times 10^{6}$ & $3,4 \times 10^{7}$ & $1,2 \times 10^{7}$ & $1,5 \times 10^{7}$ \\
\hline D7 & $1,3 \times 10^{7}$ & $4,4 \times 10^{7}$ & $1,4 \times 10^{7}$ & $1,6 \times 10^{7}$ \\
\hline
\end{tabular}

Fonte: Autores.

Oliveira et al. (2017) encontraram em suas pesquisas contagens de bactérias aeróbias mesófilas entre 2,0 x $10^{3}$ a 3,42 x $10^{6} \mathrm{UFC} / \mathrm{g}$ em 52 amostras. Enquanto Marchi (2006) encontrou contagens de bactérias aeróbias mesófilas, das 60 amostras analisadas, os valores entre $1,0 \times 10^{3} \mathrm{UFC} / \mathrm{g}$ a $1,0 \times 10^{8} \mathrm{UFC} / \mathrm{g}$, sendo que $75 \%$ das amostras obtiveram valores entre $10^{4}$ a $10^{6}$ UFC/g. 
Resultados semelhantes de Manfrin (2013) em seu estudo avaliando a qualidade microbiológica de carne moída bovina comercializada nos supermercados das cidades de Brasília e Taguatinga - DF, no qual encontrou contagens de bactérias aeróbias psicrotróficas $10^{6}$ e $10^{7} \mathrm{UFC} / \mathrm{g}$ em 18 amostras. Enquanto Marchi (2006) avaliando o estado de conservação de carne moída através de métodos microbiológicos e físico-químicos, encontrou resultados com a prevalência de contagens $10^{5}$ a $10^{8}$ $\mathrm{UFC} / \mathrm{g}$.

De acordo com Lundgren (2009), a legislação brasileira não defini limites em relação às contagens de microrganismos aeróbios mesófilos e psicrotróficos em carnes in natura e produtos cárneos. Porém, sabe-se que ao atingir contagens elevadas entre $10^{5}$ a $10^{6} \mathrm{UFC} / \mathrm{g}$, o alimento pode estar em processo de deterioração, ocorrendo assim, alterações nas suas características sensoriais.

Segundo a legislação paulista, que consta no Decreto $n^{\circ}$ 52.504/70, o limite máximo de microrganismos aeróbios mesófilos que devem conter na carne moída destinada ao comércio é de $5 \times 10^{5} \mathrm{UFC} / \mathrm{g}$. Os resultados apresentados no presente estudo, a maioria das amostras estão em conformidade com a legislação paulista até D3 (décimo dia de armazenamento). Portanto, a carne moída de hipermercados, bem como de mercados de bairros atendiam o exigido pela legislação. Porém, conforme o tempo de armazenamento foi aumentando, a carne estava apta ao consumo, segundo a legislação paulista, até D3, ou seja, dez dias.

Neste estudo, as altas contagens de bactérias aeróbias mesófilas e psicrotróficos podem estar associadas com a contaminação prévia dos alimentos. Essa contaminação, geralmente pode ocorrer durante o processo de abate, assim como transporte e armazenamento no estabelecimento, ou seja, durante as etapas de produção e elaboração do produto. A partir deste ponto torna-se importante as boas práticas aplicadas no comércio, como no corte e moagem da carne, utilização de utensílios higienizados, limpeza do ambiente e higiene do manipulador (Oliveira, 2012; Flores \& Melo, 2015).

Portanto, os estudos a respeito da qualidade microbiológica da carne, verificando a presença de microrganismos psicrotróficos bem como os mesófilos assumem um papel importante na saúde pública, visto que, o consumidor quando adquire esses alimentos nos estabelecimentos comerciais, não possuem a mínima noção da quantidade de microrganismo deterioradores e/ou patogênicos que podem estar contidos naquela carne (Oliveira, 2012).

\section{Mesófilos x psicrotróficos}

Na Figura 2, encontra-se a esquematização da curva de multiplicação dos microrganismos aeróbios mesófilos e psicrotróficos de hipermercados e mercados de bairros do início ao final do estudo.

Figura 2. Representação esquemática das amostras de carne moída de hipermercados (A) e mercados de bairros (B) no município de Boa Vista/RR, segundo a curva de multiplicação de microrganismos aeróbios mesófilos e psicrotróficos ao longo do tempo de armazenamento.

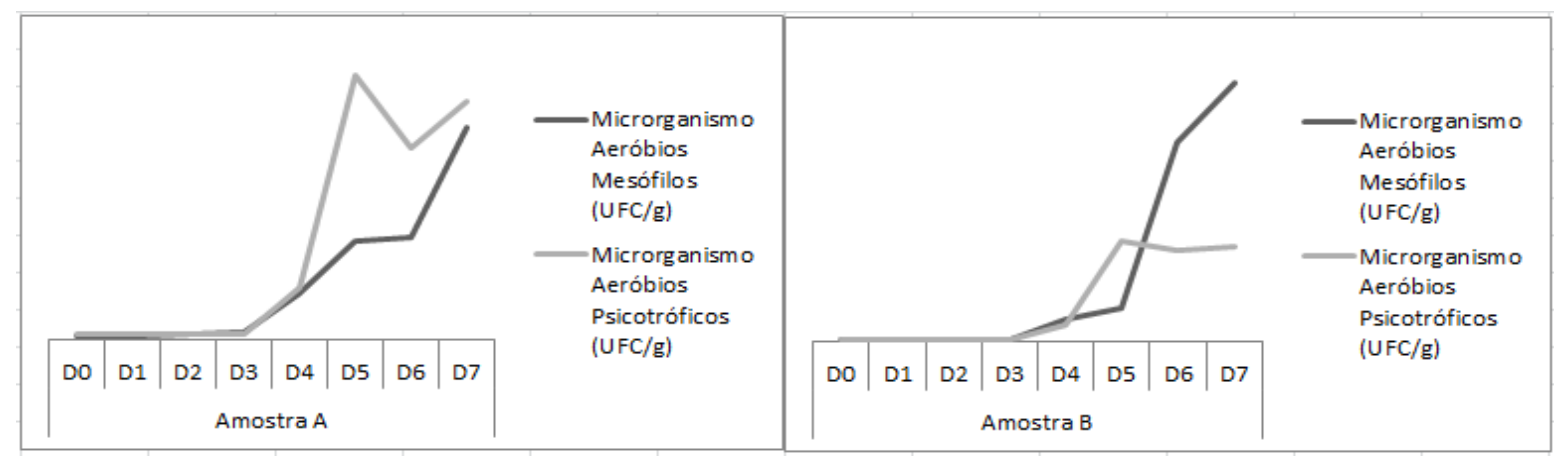

Fonte: Autores. 
Ao analisar a Figura 2, observou-se que a partir de D3 (décimo dia de armazenamento), há uma acentuada multiplicação de microrganismos aeróbios mesófilos e psicrotróficos, tanto na amostra A, quanto na amostra B. Sendo, que em D4 (décimo terceiro dia de armazenamento) houve a multiplicação exponencial altíssima nas duas amostras (A e B) desses microrganismos aeróbios. Porém, as bactérias aeróbias psicrotróficas foram as primeiras a se desenvolver, mas nem por isso as bactérias aeróbias mesofílicas deixaram de se multiplicar.

A explicação para isso está relacionada ao fato de que todo produto considerado fresco, é natural encontrar uma microbiota residindo à carne. Segundo James (1996) e Neto (2003) a carcaça bovina após a limpeza, em sua superfície apresenta entre $10^{2}$ e $10^{4} \mathrm{UFC} / \mathrm{cm}^{2}$. Levando em conta isso, as contagens elevadas de mesófilos e psicrotróficos no presente estudo, possivelmente é devido à contaminação prévia durante a fase de moagem, manipulação excessiva ou ainda a conservação em temperaturas inadequadas.

Na Figura 3, estão dispostos os resultados obtidos pelo teste $\mathrm{T}$, comparando amostras de carne moída de hipermercados e mercados de bairros em relação à contagem padrão em placas de microrganismos aeróbios mesófilos.

Figura 3. Representação esquemática das amostras de carne moída de hipermercados (A) e mercados de bairros (B) no município de Boa Vista/RR, segundo a contagem padrão em placas de microrganismos mesófilos.

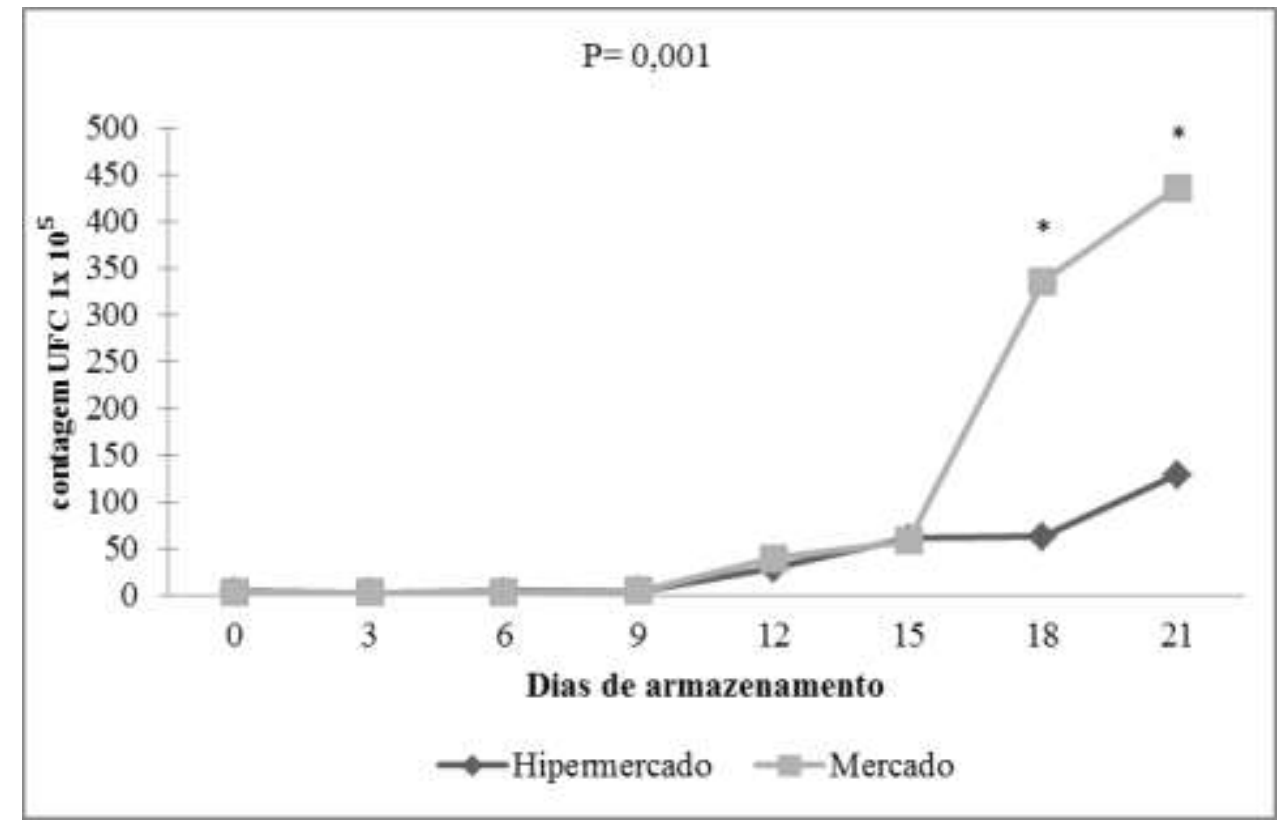

Fonte: Autores.

$\mathrm{O}$ resultado fornecido pelo teste $\mathrm{T}$ para amostras independentes, o comparativo entre amostras de carne moída de hipermercados e mercados de bairro em relação a contagem padrão em placas de microrganismos mesófilos, apresentou diferenças significativas em D6 (dezoito dias de armazenamento), cerca de 5,4\% e D7 (vinte e um dias de armazenamento) em torno de $3,4 \%$. Os demais dias, não apresentaram diferenças significativas estatisticamente.

Na Figura 4, estão dispostos os resultados obtidos pelo teste $\mathrm{T}$, comparando amostras de carne moída de hipermercados e mercados de bairros em relação à contagem padrão em placas de microrganismos aeróbios psicrotróficos. 
Figura 4. Representação esquemática das amostras de carne moída de hipermercados (A) e mercados de bairros (B) no município de Boa Vista/RR, segundo a contagem padrão em placas de microrganismos psicrotróficos.

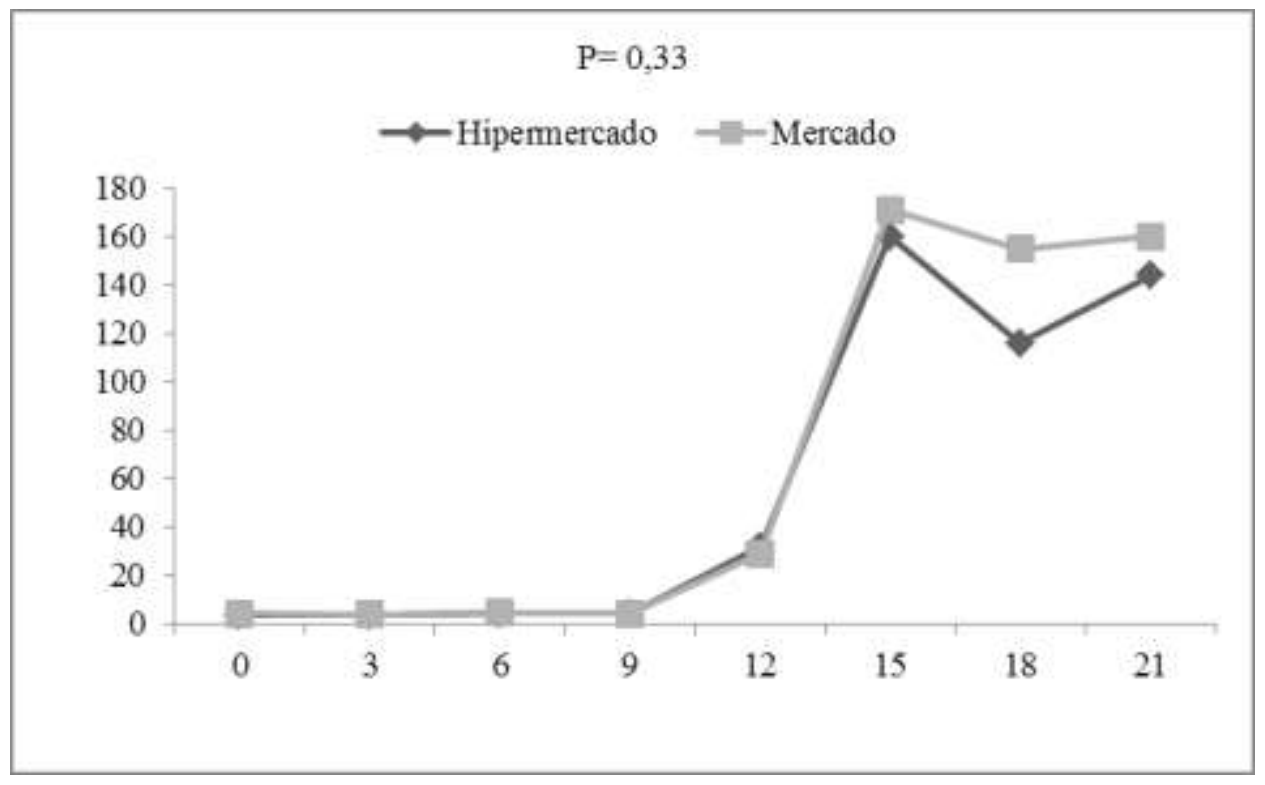

Fonte: Autores.

O resultado fornecido pelo teste T para amostras independentes, o comparativo entre amostras de carne moída de hipermercados e mercados de bairros em relação à contagem padrão em placas de microrganismos psicrotróficos, não apresentou diferenças significativas estatisticamente.

\section{Análise sensorial $\mathrm{X}$ pH X contagem microbiana}

De acordo com os resultados apresentados neste estudo, a vida útil da carne moída de hipermercados e mercados de bairros em relação a análise sensorial foi em torno de sete dias de armazenamento. Zamora e Zaritzky (1985) em seus resultados apontam para oito dias a vida útil de carnes moídas em embalagens permeáveis, mantidas a $4^{\circ} \mathrm{C}$.

Em relação ao $\mathrm{pH}$, os valores encontrados estão em conformidade com a legislação brasileira vigente até o primeiro dia de armazenamento. Quanto às contagens microbianas de bactérias aeróbias mesófilas e psicrotróficas na carne moída de hipermercados e mercados de bairros, segundo a legislação, a vida útil foi de dez dias de armazenamento.

O consumidor ao adquirir esse alimento, visualmente pode escolher carnes de qualidade por meio de características sensoriais do produto, eliminando aquelas que apresentarem características duvidosas, e fica evidente a importância do armazenamento sob refrigeração. Sob o ponto de vista microbiológico e pH das carnes, o consumidor no momento da compra, não tem acesso a essas informações.

\section{Conclusão}

A vida útil da carne moída de hipermercados e mercados de bairros comercializadas no município de Boa Vista-RR, mantida sob refrigeração, em relação a análise sensorial é em torno de sete dias. Em relação à contagem bacteriana a carne estava apta para consumo até o décimo dia de armazenamento. Enquanto os valores de pH atendem a legislação brasileira vigente, somente no primeiro dia de armazenamento.

É necessário a aplicação de Boas Práticas de Fabricação no comércio, no intuito de garantir segurança dos alimentos para população e também é necessários mais estudos a respeito do assunto na região. 


\section{Referências}

Aberle, E. D. et al. (2001). Principles of meat science. (4a ed.) Dubuque, Iowa: Kendall Hunt Publishing Company, 353 p.

Bandeira, M. T. P. S. (2004). Qualidade microbiológica da carne bovina. 43 f. Monografia (Especialização em Qualidade em Alimentos) - Universidade de Brasília, Brasília, 2004.

Barbosa, N. C. et al. (2020). Qualidade microbiológica de lombo suíno e correlação entre microrganismos indicadores. Brazilian Journal of Development, p. 24591-24600.

Brasil. Ministério da Agricultura, Pecuária e Abastecimento. (1981). Secretaria Nacional de Defesa Agropecuária. Laboratório Nacional de Referência Animal (LANARA). Aprova os Métodos Analíticos Oficiais para Controle de Produtos de Origem Animal e seus Ingredientes: métodos físicos e químicos. Portaria ${ }^{\circ}$ 01, de 07 de outubro de 1981. Diário Oficial da União. Brasília, DF.

Brasil. Ministério da Agricultura, Pecuária e Abastecimento. (1997). Aprova o Regulamento Técnico sobre as Condições Higiênico-Sanitárias e de Boas Práticas de Elaboração para Estabelecimentos Elaboradores/Industrializadores de Alimentos. Portaria n. 368 , de 04 de setembro de 1997. Diário Oficial da República Federativa do Brasil, Brasília, DF.

Brasil. Ministério da Agricultura, Pecuária e Abastecimento. (2003) Aprova os Regulamentos Técnicos de Identidade e Qualidade de Carne Bovina em Conserva e Carne Moída de Bovino. Instrução Normativa nº 83, de 21 de novembro de 2003. Diário Oficial da União, Brasília, DF.

Conceição, F. V. E. \& Gonçalves, É. C. B. A. (2009). Qualidade físico-química de mortadelas e carnes moídas e conhecimento dos consumidores na conservação destes produtos. Food Science and Technology, p. 283-290.

Cunha, M. R. S. M. (2018). Avaliação das condições higiênico-sanitárias da produção e comercialização do peixe salgado seco na cidade de Luanda. Tese de Doutorado. Universidade de Lisboa, Faculdade de Medicina Veterinária.

Downes, F. P. \& Ito, K. (2001). Compedium of methods for the microbiological examination of foods. (4a ed.), Washington: American Public Health Association, $676 \mathrm{p}$.

Ferreira, R. S. \& Simm, E. M. (2012). Análise microbiológica da carne moída de um açougue da região central do município de Pará de Minas/MG. Revista Digital FAPAM. 1(3):37-61. https://periodicos.fapam.edu.br/index.php/synthesis/article/view/50.

Flores, A. M. P. C. \& Melo, C. B. (2015). Principais bactérias causadoras de doenças de origem alimentar. Revista Brasileira de Medicina Veterinária. 37(1): 65-72.

James, S. (1996). The The chill chain "from carcass to consumer". Meat Science Journal, Chicago, p. 203-216.

Lundgren, P. U. et al. (2009). Perfil da qualidade higiênico-sanitária da carne bovina comercializada em feiras livres e mercados públicos de João Pessoa/PBBrasil. Alimentos e Nutrição, Araraquara, p. 113-119.

Mach, N. et al. (2008). Association between animal, transportation, slaughterhouse practices, and meat pH in beef. Meat Science, $232-238$.

Mancini, R. A. \& Hunt, M. C. (2005). Current research in meat color. Meat Science, Barking, p. 100-121.

Manfrin, L. C. (2013). Avaliação da qualidade microbiológica de carne moída bovina comercializada nos supermercados das cidades de Brasília e Taguatinga-DF. 2013. 61 f. Monografia (Bacharelado em Farmácia) - Universidade de Brasília, Brasília.

Marchi, P. Estudo comparativo do estado de conservação de carne moída através de métodos microbiológicos e físico-químicos. (2006). 35-36 f. Dissertação (Mestrado em Medicina Veterinária Preventiva) - Faculdade de Ciências Agrárias e Veterinárias, Universidade Estadual Paulista, São Paulo.

Neto, M. P. (2003). Embalagem da carne vermelha. Revista Nacional da Carne, 110-123.

Oliveira, D. T. et al. (2012). Psicrotróficos na indústria de laticínios. In: Seminário Interinstitucional de Ensino, Pesquisa e Extensão, (17), 2012, RS. Anais... Cruz Alta: UNICRUZ, p. 1-2.

Oliveira, A. (2012). Alimentação de bovinos de corte: nutrientes. http://www.cpt.com.br/cursos-bovinos-gadodecorte/artigos/alimentacao-de-bovinos-decorte-nutrientes\#ixzz2Zi1FJmuU.

Ornellas, L. H. (2001). Técnica dietética: seleção e preparo de alimentos. (7a ed.), Atheneu.

Roça, R. O. Refrigeração, (2008). https://www.fca.unesp.br/Home/Instituicao/Departamentos/Gestaoetecnologia/Teses/Roca108.pdf.

Silva, E. A. (2002). Manual de controle higiênico-sanitário em alimentos. (5a ed.), Varela.

Skrökki, A. (1997). Hygienic quality of commercial minced mest as indicated by aerobic micro-organisms and coliform bacteria. Zeitschrift Fuer Lebensmittel Untersuchung Und Florschung, p. 391-394.

Souza, A. C. F. et al. (2020). Análises físico-químicas e microbiológicas da carne moída comercializada em açougues de três bairros da Zona Sul de MacapáAmapá. Research, Society and Development, 9(3), e182932708. http://dx.doi.org/10.33448/rsd-v9i4.2708

Souza, E. L. \& Silva, C. A. (2004). Qualidade sanitária de equipamentos, superfícies, água e mãos de manipuladores de alguns estabelecimentos que comercializam alimentos na cidade de João Pessoa, PB. Revista Higiene Alimentar, 98-102.

Zamora, M. C. \& Zaritzky, N. E. (1985). Modeling of microbial growth in refrigerated packaged beef. Food Science, $1003-1006$. 